\title{
Perspectives on Chemical Modification of Carbon Nanomaterials Assisted by Microwave Radiation
}

\author{
Hélio Ribeiro ${ }^{1 *}$ and DN Vilela ${ }^{2}$ \\ ${ }^{1}$ Universidade Federal de Minas Gerais, Belo Horizonte, Brazil \\ ${ }^{2}$ Centro Universitário Barão de Mauá, Ribeirão Preto, Brazil
}

*Corresponding author: Hélio Ribeiro, Chemistry Department, Universidade Federal de Minas Gerais, Av. Antônio Carlos, 6627-Pampulha, CEP 31270901, Belo Horizonte-MG, Brazil, Tel: +55-31-988886023; Email: helioribeiro@hotmail.com

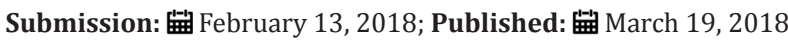

\begin{abstract}
Carbon nanomaterials (CNMs) as graphene and carbon nanotubes (CNTs) have attracted attention of scientific community due to their high performance and applications. However, their potential applications as nanofillers, depends necessarily of their production which high structural quality, great compatibility with the host system. For instance, in polymeric matrices this issue involves several challenges due to their low dispersibility in water and organic solvents, thus different process of chemical modification of CNMs surfaces have been reported. In cases of functionalization with amino groups, most of them use in one of their chemical steps thionyl chloride (SOCl2) as intermediate reagent. In general, the use of SOCl2 limits the chemical process, due to of its dangerous nature and high level of toxicity. Another drawback found in this kind of methodology is the time spent on reflux lasting days and making it a very onerous process. In this context, the chemical modification of CNMs assisted by microwave radiation has been explored in synthesis, purification and chemical modification processes of these nanostructures resulting in simpler and faster procedures that allow its used on a large scale and with low environmental impact.
\end{abstract}

Keywords: Carbon nanomaterials; Graphene; Carbon nanotubes; Chemical functionalization; Microwave irradiation

\section{Mini Review}

CMNs as graphene and carbon nanotubes exhibit exceptional physical properties that have generated great interest from the scientific and technological community [1-4]. Graphene can be understood as a single stable 2D graphite layer formed only by carbon atoms hybridized in $\mathrm{sp}^{2}$ and arranged in hexagonal rings, that theoretically is considered as a fundamental block for the construction of other allotropic covalent carbon solids, such as graphite, fullerenes and CNTs [5]. In order, the development of several methods of production of graphene and carbon nanotubes has been gaining relevance because their nanostructure exhibits excellent electrical, thermal and mechanical high flexibility. In special, CNTs have been studied in approximately the last two decades by many researchers due to their great potential application in different fields [6]. Their important features such as light weight, high aspect ratio, and impressive tensile strength, thermal and electrical conductivity make them useful as nano additives in different polymers and ceramics systems [7]. On the other hand, it was observed that graphene presents high electrical mobility $\left(200.000 \mathrm{~cm}^{2} \mathrm{~V}^{-1} \mathrm{~s}^{-1}\right)$ [8], two orders of magnitude greater than the silicon and its electric transport occurs from ballistic form at room temperature [5]. Graphene showed thermal conductivity of approximately $5.000 \mathrm{Wm}^{-1} \mathrm{~K}^{-1}$ [9], and high surface area $\left(2.630 \mathrm{~m}^{2} \mathrm{~g}^{-1}\right)$ [10]. Moreover, it is important to mention that graphene presents a modulus of elasticity of $1.1 \mathrm{GPa}$ and tensile strength of $125 \mathrm{GPa}, 200$ times greater than steel [11]

Different methods of synthesis of CNMs, such as chemical vapor deposition (CVD), electric arc discharge, epitaxial growth on SiC substrate, reduction of CO, opening of CNTs (bottom-up) and graphite exfoliation (top-down) [12-16], have been reported. Microwave-assisted procedures have been used in methodologies for the growth of graphene films via CVD [17], as well as chemical exfoliation processes of graphite to produce graphene oxide (GO) nanosheets $[15,18,19]$. Chemical functionalization of CNMs and their applications such as reinforcing polymers composites, supercapacitors, cells solar cells, memory devices, biosensors, drug dispensers [4,12,20-32] among other, also have been reported.

The ability to control the functionalities of CNMs surface is importance for exploring and building blocks in the engineering of supra-molecular structures, that imparting them specific solubility in specific solvents or host matrices [33]. In general, to produce a more reactive CNMs surface in different substrates, chemical groups may be covalently introduced on their surface [5,24,34]. In case of graphene, graphite and CNTs, this type of procedure needs to be controlled duo to the inherent re-hybridization process of carbon atoms $\mathrm{sp}^{2}$ to $\mathrm{sp}^{3}$. This process is accompanied by the partial 
or total loss of $\pi-\pi$ electronic conjugation that alter significantly their electrical properties $[5,22,26,35,36]$. To overcome this issue, one strategy adopted is the doping of the crystalline network of CNMs with hetexroatoms such as $\mathrm{N}, \mathrm{P}$ and $\mathrm{B}$ without destroying their structural integrity, thus preserving their potential properties $[20,22,37]$ however, this task is not easy.

Several studies have been carried out to develop effective CNMs fictionalization process, and most of them adopted the strategy based on processes of carboxylation. This reaction has advantages in that the carboxylated groups can be derivatized to ester, amides and isocyanates $[33,38]$. However, many works with amino-functionalization reaction in CMNs, report processes via SOCl2 (Figure 1). Niyogi et al. [34] reported an effective way of obtaining graphene oxide functionalized with octadecylamine (ODA) after the treatment of graphite oxide with sulfuric acid, followed by treatment with thionyl chloride $\left(\mathrm{SOCl}_{2}\right)$ and ODA, forming GO-ODA. Hu Y et al. [6] were able to functionalize CNMs with 4,4'-diaminodiphenylsulfono (DDS) in dimethylformamide (DMF) at $130{ }^{\circ} \mathrm{C}$ under inert atmosphere at reflux for 6 days. Silva et al. [7] modified covalently CNTs with triethylenetetramine groups (TETA). Initially, they used as the reaction mixture in the presence of distilled $\mathrm{SOCl}_{2}$ and maintained under reflux for 24 hours. After reflux, all $\mathrm{SOCl}_{2}$ was extracted from the medium by distillation. Then, excess TETA was added in volumetric flask and kept under reflux for 72 hours [7]. This classical amino-functionalization reaction with $\mathrm{SOCl}_{2}$ has resulted in some difficulties and inconveniences, since thionyl chloride has a high degree of toxicity, and high carcinogenic potential. $\mathrm{SOCl}_{2}$ reacts violently in contact with water, releasing acid gases and, in contact with metal surfaces, can generate flammable and explosive hydrogen. Generally, this methodology requires approximately 96 hours or up to 6 days, which makes the procedure very onerous $[7,39]$.

On the other hand, several chemical modification methodologies assisted by microwave have been reported [16,19,20,40-46]. In general, the irradiation process can be used in mild conditions, with controlled temperatures and reduced time reaction, when compared to conventional techniques (Figure 1) [13,33,41,46-48]. An advantage of use microwave radiation that only 3 minutes of irradiation in CNTs samples (in $\mathrm{H}_{2} \mathrm{SO}_{4} / \mathrm{HNO}_{3}$ mixture) is sufficient to produce carboxyl groups promoting their dispersibility in water [48]. Amidation, esterification and cycle addition reactions in CNMs surface assisted by microwave in several solvent systems and ionic liquids have also been reported [49-52]. The introduction of amide groups in GO surface in only 30 minutes without the use of $\mathrm{SOCl}_{2}$, was reported by Ribeiro et al. [33].

\section{A - Conventional method}

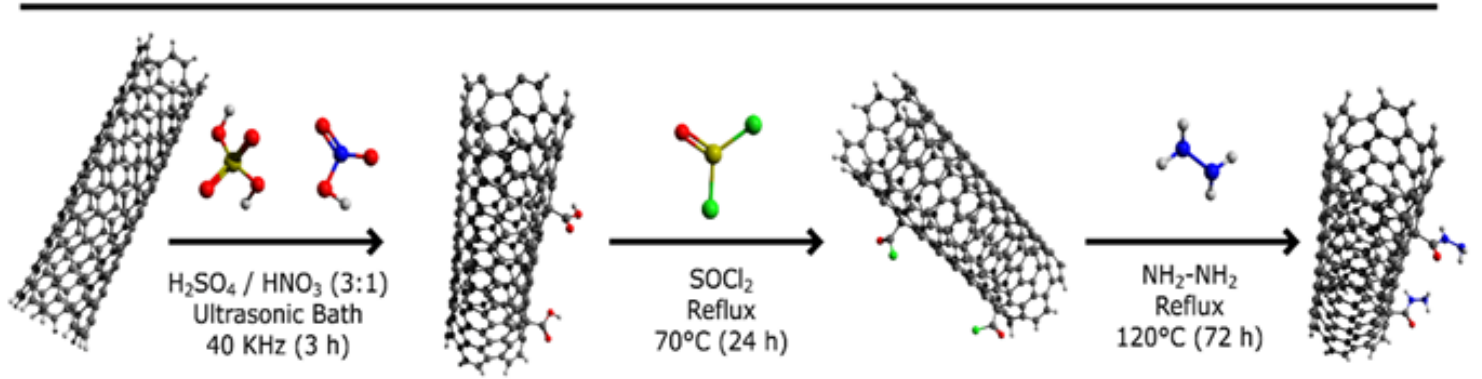

\section{B - Microwave method}

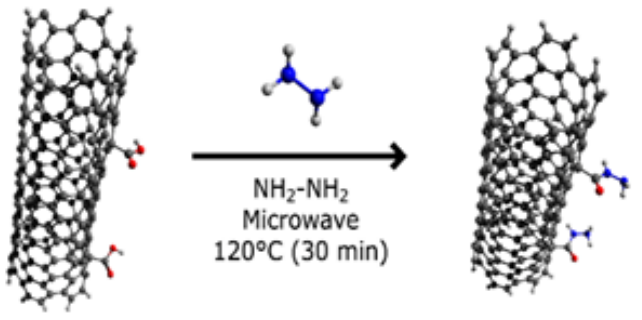

Figure 1: Different routes of chemical functionalization of CNMs with amide groups.

1a: Conventional method and

1b: Assisted by microwave radiation.

Several other methodologies of chemical modification of CNMs assisted by microwave have led to the formation of CNMs functionalized with different groups in a smaller reaction time [46], some of them are summarized in the Table 1. 
Table 1: Synthesis and chemical functionalization methodologies of CNMs assisted by microwave radiation.

\begin{tabular}{|c|c|c|}
\hline Nanomaterials & Methodology & Reference \\
\hline Graphene Oxide & $\begin{array}{l}\text { The addition of a small amount graphene oxide leads to deoxygenation reaction of GO under } \\
\text { microwave irradiation and graphene formation. }\end{array}$ & [41] \\
\hline MWCNTs & $\begin{array}{l}\text { Multi-walled carbon nanotubes (MWCNTs) synthesized by thermal chemical vapor deposition } \\
\text { have been successfully purified by high efficient microwave acid digestion method. }\end{array}$ & [53] \\
\hline Carbon nanotubes & Interaction study of carbon nanotubes and microwaves, responses, and applications & [46] \\
\hline MWCNTs-NCO & $\begin{array}{l}\text { Microwave-assisted functionalization of carbon nanotubes with isocyanate groups allowed } \\
\text { a reduction of functionalization time from } 24 \mathrm{~h} \text { to } 30 \text { minute with no change in the degree of } \\
\text { functionalization or in the nanotube characteristics. }\end{array}$ & [38] \\
\hline Carbon black & $\begin{array}{l}\text { Carbon black surfaces were sequentially modified with ethylenediamine by microwave } \\
\text { irradiation. }\end{array}$ & [54] \\
\hline Graphite & $\begin{array}{l}\text { Versatile method to achieve the exfoliation and reduction of graphite oxide assisted by } \\
\text { microwave reaction. }\end{array}$ & [55] \\
\hline Graphene & $\begin{array}{l}\text { Chemical reduction method assisted by microwave irradiation for the synthesis of chemically } \\
\text { converted graphene sheets and metal nanoparticles dispersed on the graphene sheets. }\end{array}$ & [44] \\
\hline Graphene-chitosan & $\begin{array}{l}\text { Chitosan (CS) modified graphene nanosheets were prepared under microwave irradiation in } \\
\qquad \mathrm{N}, \mathrm{N} \text {-dimethylformamide medium. }\end{array}$ & [19] \\
\hline Mos2/graphene & $\begin{array}{l}\text { Graphene-based molybdenum disulfide catalyst was prepared via a microwave irradiation } \\
\text { assisted route. }\end{array}$ & [51] \\
\hline MWCNTs- bisphenol-A-polycarbonate & $\begin{array}{l}\text { MWNTs were grafted with bisphenol-A-polycarbonate in a solid state reaction at } 110^{\circ} \mathrm{C} \text { using } \\
\text { microwave irradiation. }\end{array}$ & [56] \\
\hline
\end{tabular}

These techniques have also been used in several CNMs grafting procedures in polymeric molecules [56,57], and in catalytic systems such as hydrodesulfurization reactions [51]. Thus, chemical manipulation processes of CNMs assisted by microwave have often used in methodologies for the synthesis, purification and functionalization of CNMs samples, providing simple, easy methodologies that allow us used it in large scale.

\section{Conclusion}

The microwave-activated chemical reactions cover a wide spectrum of potential applications for the chemical manipulation of CNMs, providing a fast, compact, simple, selective, and economical technique. In addition, the reaction system can evolve under mild conditions in the absence of toxic reagents (such as $\mathrm{SOCl}_{2}$ ), and without the use of long heating time, as seen in the classical refluxes. Further studies on the behavior of CNMs as graphene and CNTs in different systems activated by microwaves should be explored opening new perspectives in their applications in different areas of science and technology.

\section{References}

1. Novoselov KS, Geim AK, Morozov SV, Jiang D, Zhang Y, et al. (2004) Electric field effect in atomically thin carbon films. Science 306(5696): 666-669.

2. Novoselov KS, Geim AK, Morozov SV, Jiang D, Katsnelson MI, et al. (2005) Two-dimensional gas of massless Dirac fermions in graphene. Nature 438: 197.

3. Zhang Y, Tan YW, Stormer HL, Kim P (2005) Experimental observation of the quantum Hall effect and Berry's phase in graphene. Nature 438(7065): 201-204.

4. Geim AK, Novoselov KS (2007) The rise of graphene. Nat Mater 6(3): 183-191.
5. Terrones M, Martín O, González M, Pozuelo J, Serrano B, et al. (2011) Interphases in graphene polymer-based nanocomposites: achievements and challenges. Adv Mater 23(44): 5302-5310.

6. Hu Y, Shen J, Li N, Ma H, Shi M, et al. (2010) Comparison of the thermal properties between composites reinforced by raw and aminofunctionalized carbon materials. Compos Sci Technol 70(15): 21762182.

7. Silva WM, Ribeiro H, Seara LM, Calado HD, Ferlauto AS, et al. (2012) Surface properties of oxidized and aminated multi-walled carbon nanotubes. J Braz Chem Soc 23(6): 1078-1086.

8. Bolotin KI, Sikes KJ, Jiang Z, Klima M, Fudenberg G, et al. (2008) Ultrahigh electron mobility in suspended graphene. Solid State Commun 146(9): 351-355.

9. Balandin AA, Ghosh S, Bao W, Calizo I, Teweldebrhan D, et al. (2008) Superior thermal conductivity of single-layer graphene. Nano Lett 8(3): 902-907.

10. Stoller MD, Park S, Zhu Y, An J, Ruoff RS (2008) Graphene-based ultracapacitors. Nano Lett 8(10): 3498-3502.

11. Lee C, Wei X, Kysar JW, Hone J (2008) Measurement of the elastic properties and intrinsic strength of monolayer graphene. Science 321 (5887): 385-388.

12. Allen MJ, Tung VC, Kaner RB (2010) Honeycomb carbon: a review of graphene. Chem Rev 110(1): 132-145.

13. Tang P, Hu G, Gao Y, Li W, Yao S, et al. (2014) The microwave adsorption behavior and microwave-assisted heteroatoms doping of graphenebased nano-carbon materials. Sci Rep 4: 5901.

14. Kim H, Abdala AA, Macosko CW (2010) Graphene/polymer nanocomposites. Macromolecules 43(16): 6515-6530.

15. TK BS, Nair AB, Abraham BT, Beegum PMS, Thachil ET (2014) Microwave exfoliated reduced graphene oxide epoxy nanocomposites for high performance applications. Polymer 55(16): 3614-3627.

16. Xiao L, Liao L, Liu L (2013) Chemical modification of graphene oxide with carbethoxycarbene under microwave irradiation. Chem Phys Lett 556: 376-379. 
17. Kalita G, Wakita K, Umeno M (2012) Low temperature growth of graphene film by microwave assisted surface wave plasma CVD for transparent electrode application. RSC Adv 2(7): 2815-2820.

18. Siamaki AR, Khder AERS, Abdelsayed V, El-Shall MS, Gupton BF (2011) Microwave-assisted synthesis of palladium nanoparticles supported on graphene: A highly active and recyclable catalyst for carbon-carbon cross-coupling reactions. J Catal 279(1): 1-11.

19. Hu H, Wang X, Wang J, Liu F, Zhang M, et al. (2011) Microwave-assisted covalent modification of graphene nanosheets with chitosan and its electrorheological characteristics. Appl Surf Sci 257(7): 2637-2642.

20. Shi G, Hanlumyuang Y, Liu Z, Gong Y, Gao W, et al. (2014) Boron nitridegraphene nanocapacitor and the origins of anomalous size-dependent increase of capacitance. Nano Lett 14 (4): 1739-1744

21. Liu W, Kraemer S, Sarkar D, Li H, Ajayan PM, et al. (2014) Controllable and rapid synthesis of high-quality and large-area bernal stacked bilayer graphene using chemical vapor deposition. Chem Mater 26 (2): 907-915.

22. Chua CK, Pumera M (2014) Chemical reduction of graphene oxide: a synthetic chemistry viewpoint. Chem Soc Rev 43 (1): 291-312.

23. Tang LC, Wan YJ, Yan D, Pei YB, Zhao L, et al. (2013) The effect of graphene dispersion on the mechanical properties of graphene/epoxy composites. Carbon 60: 16-27.

24. Shen Y, Lua AC (2013) A facile method for the large-scale continuous synthesis of graphene sheets using a novel catalyst. Sci Rep 3: 3037

25. Wan YJ, Tang LC, Yan D, Zhao L, Li YB, et al. (2013) Improved dispersion and interface in the graphene/epoxy composites via a facile surfactantassisted process. Compos Sci Technol 82: 60-68.

26. Kuila T, Bose S, Mishra AK, Khanra P, Kim NH, et al. (2012) Chemical functionalization of graphene and its applications. Prog Mater Sci 57(7): 1061-1105.

27. Zhu Y, Murali S, Cai W, Li X, Suk JW, et al. (2010) Graphene and graphene oxide: synthesis, properties, and applications. Adv Mater 22(35): 39063924.

28. Du J, Cheng HM (2012) The fabrication, properties, and uses of graphene polymer composites. Macromol Chem Phys 213(10-11): 1060-1077.

29. Hong BH (2011) In synthesis and applications of graphene for flexible electronics, $69^{\text {th }}$ DRC: pp 37-38.

30. Fuhrer MS, Lau CN, MacDonald AH (2011) Graphene: materially better carbon. MRS Bull 35(4): 289-295.

31. Kuilla T, Bhadra S, Yao D, Kim NH, Bose S, et al. (2010) Recent advances in graphene based polymer composites. Prog Polym Sci 35(11): 13501375.

32. Geim AK (2009) Graphene: status and prospects. Science 324(5934): $1530-1534$

33. Ribeiro H, da Silva WM, Neves JC, Calado HDR, Paniago R, et al. (2015) Multifunctional nanocomposites based on tetraethylenepentaminemodified graphene oxide/epoxy. Polym Test 43: 182-192.

34. Niyogi S, Bekyarova E, Itkis ME, McWilliams JL, Hamon MA, et al. (2006) Solution properties of graphite and graphene. J Am Chem Soc 128(24): 7720-7721.

35. Park MJ, Lee JK, Lee BS, Lee YW, Choi IS, et al. (2006) Covalent modification of multiwalled carbon nanotubes with imidazolium-based ionic liquids: effect of anions on solubility. Chem Mater 18(6): 1546-1551.

36. Moniruzzaman M, Winey KI (2006) Polymer nanocomposites containing carbon nanotubes. Macromolecules 39(16): 5194-5205.

37. Gong Y, Shi G, Zhang Z, Zhou W, Jung J, et al. (2014) Direct chemical conversion of graphene to boron-and nitrogen-and carbon-containing atomic layers. Nat Commun 5: 3193.

38. Lopes MC, Ribeiro H, Santos MCG, Seara LM, Ferreira FLQ (2017) High performance polyurethane composites with isocyanate-functionalized carbon nanotubes: Improvements in tear strength and scratch hardness. J Appl Polym Sci 134 (2): 44394.

39. Ribeiro H, Silva WM, Rodrigues MTF, Neves JC, Paniago R, et al. (2013) Glass transition improvement in epoxy/graphene composites. J Mater Sci 48(22): 7883-7892.

40. Leng X, Xiong X, Zou JP (2014) Rapid microwave irradiation fast preparation and characterization of few-layer graphenes. Trans Nonferrous Met Soc China 24(1): 177-183.

41. Hu H, Zhao Z, Zhou Q Gogotsi Y, Qiu J (2012) The role of microwave absorption on formation of graphene from graphite oxide. Carbon 50(9): 3267-3273.

42. Chen W, Yan L, Bangal PR (2010) Preparation of graphene by the rapid and mild thermal reduction of graphene oxide induced by microwaves. Carbon 48(4): 1146-1152.

43. Luo Z, Lu Y, Somers LA, Johnson ATC (2009) High yield preparation of macroscopic graphene oxide membranes. J Am Chem Soc 131(3): 898899.

44. Hassan HMA, Abdelsayed V, Khder AERS, AbouZeid KM, Terner J, et al. (2009) Microwave synthesis of graphene sheets supporting metal nanocrystals in aqueous and organic media. J Mater Chem 19(23): 38323837.

45. Guo S, Wen D, Zhai Y, Dong S, Wang E (2010) Platinum nanoparticle ensemble-on-graphene hybrid nanosheet: one-pot, rapid synthesis, and used as new electrode material for electrochemical sensing. ACS Nano 4(7): 3959-3968.

46. Vázquez E, Prato M (2009) Carbon nanotubes and microwaves: interactions, responses, and applications. ACS Nano 3(12): 3819-3824.

47. Ikeda T, Kamo T, Danno M (1995) New synthesis method of fullerenes using microwave-induced naphthalene-nitrogen plasma at atmospheric pressure. Appl Phys Lett 67(7): 900-902.

48. Wang Y, Iqbal Z, Mitra S (2006) Rapidly functionalized, water-dispersed carbon nanotubes at high concentration. J Am Chem Soc 128(1): 95-99.

49. Kakade BA, Pillai VK (2008) An efficient route towards the covalent functionalization of single walled carbon nanotubes. Appl Surf Sci 254(16): 4936-4943.

50. Raghuveer MS, Agrawal S, Bishop N, Ramanath G (2006) Microwaveassisted single-step functionalization and in situ derivatization of carbon nanotubes with gold nanoparticles. Chem Mater 18(6): 1390-1393.

51. Liu N, Wang X, Xu W, Hu H, Liang J, et al. (2014) Microwaveassisted synthesis of $\mathrm{MoS}_{2}$ /graphene nanocomposites for efficient hydrodesulfurization. Fuel 119: 163-169.

52. Guryanov I, Toma FM, López AM, Carraro M, Da Ros T, et al. (2009) Microwave-assisted functionalization of carbon nanostructures in ionic liquids. Chem Eur J 15 (46): 12837-12845.

53. Chen CM, Chen M, Peng YW, Yu HW, Chen CF (2006) High efficiency microwave digestion purification of multi-walled carbon nanotubes synthesized by thermal chemical vapor deposition. Thin Solid Films 498(1-2): 202-205

54. Lima MCFS, Amparo SZ, Ribeiro H, Soares AL, Viana MM (2016) Aqueous suspensions of carbon black with ethylenediamine and polyacrylamidemodified surfaces: Applications for chemically enhanced oil recovery. Carbon 109: 290-299. 
55. Zhu Y, Murali S, Stoller MD, Velamakanni A, Piner RD (2010) Microwave assisted exfoliation and reduction of graphite oxide for ultracapacitors. Carbon 48(7): 2118-2122.

56. Mormann W, Lu Y, Zou X, Berger R (2008) Modification and grafting of multi-walled carbon nanotubes with bisphenol-a-polycarbonate.
Macromol Chem Phys 209(20): 2113-2121.

57. Bokobza L (2007) Multiwall carbon nanotube elastomeric composites: A review. Polymer 48(17): 4907-4920. (c) (i) Creative Commons Attribution 4.0 International License

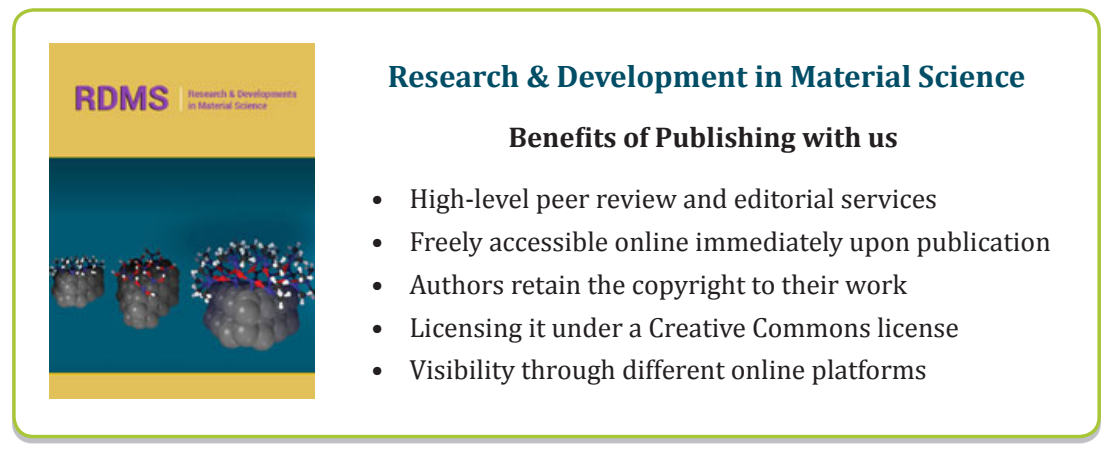

